\title{
Cannabis abuse and psychiatric disorder
}

\author{
John Tobin
}

Ir J Psych Med 2004; 21(3): 77

After the increases in cannabis use during the early 1990s in Europe and North America, uncertainty persists about its psychological consequences.' Overall our knowledge of the mental health effects of cannabis abuse is limited because of the difficulties in studying this topic. Studies are complicated by many confounding variables. Examples are questions like, are people who are likely to develop mental disorders more likely to abuse cannabis? Do people with mental disorders self medicate with cannabis for its sedative effects? Are people from a socially disadvantaged background who are more likely to develop mental disorders, also more likely to abuse cannabis? Though many studies have been done there is a very limited amount of evidence that stands up to detailed scrutiny. What follows are some of those findings.

Studies have demonstrated that cannabis intoxication can lead to acute transient psychotic episodes in some individuals. ${ }^{2}$ Cannabis use confers a twofold relative risk for the development of schizophrenia. ${ }^{3}$ It is estimated that the removal of cannabis abuse from 15 year olds would reduce the later development of schizophrenia in that population by $8 \%{ }^{4}$ Given that schizophrenia affects $1 \%$ of the population, an $8 \%$ reduction is not insignificant from a public health point of view. For this reason it is important to concentrate cannabis reduction policies on the young.

With the increase in cannabis abuse among adolescents there is evidence of an increase in the incidence of schizophrenia in some areas of London. ${ }^{6}$ It appears that the majority of young people are able to use cannabis in adolescence without harm, but there is a vulnerable minority that are at risk of developing a psychotic illness. For this reason there is an argument for lawmakers to encourage a delay in the onset of cannabis use. ${ }^{3}$ In Ireland $24 \%$ of those aged between 15 and 24 years report that they have used cannabis, with one in seven reporting its use in the previous month. ${ }^{8}$

Heavy cannabis use leads to a modest likelihood of developing depression. ${ }^{7}$ Much of this depression is of a brief recurrent nature. Chronic daily users report high levels of anxiety, depression, fatigue, and low motivation. ${ }^{8}$ These symptoms are more frequent in young women than in men of a similar age. ${ }^{\theta}$ In particular, frequent cannabis use in teenage girls leads to higher rates of anxiety and depression. ${ }^{10}$

Withdrawal symptoms following cessation of heavy cannabis use have been reported. ${ }^{11}$ These withdrawal symptoms include aggression, anger, anxiety, decreased appetite, restlessness, tremor, abdominal pains, and sleeping difficulties. Following cessation the withdrawal symptoms start on day one to three, peak on day two to six and last from four to 14 days.

John Tobln, MRCPsych, FRCPC, BSc, Consultant Psychiatrist, St Bricin's Military Hospital, Infirmary Road, Dublin 7, Ireland. SUBMITTED: MAY 31, 2004. ACCEPTED: JULY 8,2004
In order to obtain an overview of the psychological effects on mood, cognition and mental functioning the National Advisory Committee on Drugs commissioned a detailed overview from researchers at the National University of Ireland. ${ }^{12}$ Their findings are expected in 2004.

Cannabis is not a benign drug, its use especially in large amounts places some individuals at risk for the subsequent development of serious psychiatric illness.

The re-classification by the British Government of cannabis from a Class B to a Class C drug on the January 29, 2004 (Misuse of Drugs Act 1971) has once again opened the debate within Ireland as to whether this drug should be decriminalised..$^{13}$ The drug still remains illegal within the UK.

A recent submission to the Department of Health by the Irish Psychiatric Association ${ }^{14}$ has pointed out that it is not possible to specifically identify those individuals at risk of developing psychiatric illness secondary to cannabis abuse. In such circumstances they have recommended that the population as a whole should be protected from it. In this regard its potential increased availability and decriminalisation are judged to be premature and misguided. The risk of psychiatric illness outweighs any criminological considerations, and the policy for its decriminalisation is driven more by matters related to criminology than to medicine.

Evidence for its medical use in such conditions as multiple sclerosis and severe pain associated with end of life conditions are considered to be weak. ${ }^{15}$ In any case there are better and more effective medications available. Overall, the potential price that would be paid by some vulnerable individuals by the decriminalising of cannabis would be too high when compared to the limited benefit that would be obtained by other members of society.

\section{References}

1. Strang J, Wilton J, Hall W. Improving the quality of the Cannabis Debate; Defining the different domains. BMJ 2000; 320: 10B-110

2. D'Souza C, Cho HS, Perry E. A Cannabinoid Model Psychosis, dopamine-cannabinoid interaction and implications for Schizophrenia. In: DJ Castle DJ, R Murray R, eds. Marijuana and Madness. Cambridge University Press, 2004

3. Arsenault L, Cannon M, Witton J, Murray R, Causal association between cannabis and psychosis; examination of the evidence, Br J Psychiat 2004; 184: 110-117

4. Arsenault L, Cannon M, Poulton R. Cannabis use in adolescence and risk for adult psychosis; Longitudinal prospective study, BMJ 2002; 325: 1212-1213

5 . Boydell J, van Os J, Lambi M. Incidence of Schizophrenia in South-East London between 1965 5. Boydell J, van Os J, Lambi M. Incidence of

6. Drug use in lreland and Northern Ireland. First results from the 2002/2003. Drug Prevalence Survey. National Advisory Committee on Drugs and the Drug and Alcohol Information and Research Unit Bulletin, 2003; Oct 1

7. Degenhardt $L$, Hall $W$, Lynskey $M$, Exploring the association between cannabis use and depression. Addiction 2003; 98(Nov 11): 1493-1504

8. Reilly D, Didcott $R$, Switt W, Long-term cannabis use: characteristics of users in Australian rural areas. Addiction 1998; 93: 837-846

9. Thomas H. A community survey of adverse effects of cannabis use. Drug and Alcohol Dependency 1996; 42: 201-207

10. Patton G, Coffey C, Carlin J. Cannabis use and mental health in young people: cohort study, BMJ 2002; 325:1 195-1198

11. Budney AJ, Moore BA, Vandrey RG, Hughes JR, The time course and significance of cannabis withdrawal. J Abnormal Psychology 2003; 112(Aug 3): 393-402

12. National Advisory Committee on Drugs, Progress Report, July 2000-July 2003. Govemment Stationary Office p.26

13. www.drugs.gov.uk/NationalStrategy/CannabisReclassification

14. The Safety of Cannabis from a Mental Health Viewpoint, submission by the Irish Psychiatric Association 29/3/2004

15. Zajicek et al. Cannabinoids for the treatment of spasticity and other symptoms related to MS (CAMS study): multi-centre randomised placebo controlled trial. Lancet 2003; 3: 79-80 